\title{
Some convergence results for iterative sequences of Prešić type and applications
}

Mohammad Saeed Khan ${ }^{1}$, Maher Berzig ${ }^{2}$ and Bessem Samet ${ }^{3^{*}}$

* Correspondence: bessem. samet@gmail.com

${ }^{3}$ Department of Mathematics, King

Saud University, Riyadh, Saudi

Arabia

Full list of author information is

available at the end of the article

\section{Abstract}

In this article, we study the convergence of iterative sequences of Prešic type involving new general classes of operators in the setting of metric spaces. As application, we derive some convergence results for a class of nonlinear matrix difference equations. Numerical experiments are also presented to illustrate the convergence algorithms.

Mathematics Subject Classification 2000: 54H25; 47H10; 15A24; $65 \mathrm{H} 05$.

Keywords: iterative sequence, convergence, difference equation, fixed point, matrix

\section{Introduction}

In 1922, Banach proved the following famous fixed point theorem.

Theorem 1.1 (Banach [1]) Let $(X, d)$ be a complete metric space and $f: X \rightarrow X$ be a contractive mapping, that is, there exists $\delta \in[0,1)$ such that

$$
d(f x, f y) \leq \delta d(x, y), \quad \text { for all } x, y \in X .
$$

Then $f$ has a unique fixed point, that is, there exists a unique $x^{*} \in X$ such that $x^{*}=$ $f x *$ Moreover, for any $x_{0} \in X$, the iterative sequence $x_{n+1}=f x_{n}$ converges to $x^{*}$.

This theorem called the Banach contraction principle is a simple and powerful theorem with a wide range of application, including iterative methods for solving linear, nonlinear, differential, integral, and difference equations. Many generalizations and extensions of the Banach contraction principle exist in the literature. For more details, we refer the reader to [2-28].

Consider the $k$-th order nonlinear difference equation

$$
x_{n+1}=f\left(x_{n-k+1}, \ldots, x_{n}\right), \quad n=k-1, k, k+1, \ldots
$$

with the initial values $x_{0}, \ldots, x_{k-1} \in X$, where $k$ is a positive integer $(k \geq 1)$ and $f: X^{k} \leq$ $X$. Equation (1) can be studied by means of fixed point theory in view of the fact that $x^{*} \in X$ is a solution to (1)) if and only if $x^{*}$ is a fixed point of $f$, that is, $x^{*}=f\left(x^{*}, \ldots\right.$, $\left.x^{*}\right)$. One of the most important results in this direction has been obtained by Prešic in [22] by generalizing the Banach contraction principle in the following way.

Theorem 1.2 (Prešić [22]) Let $(X, d)$ be a complete metric space, $k$ a positive integer and $f: X^{k} \rightarrow X$. Suppose that 


$$
d\left(f\left(x_{0}, \ldots, x_{k-1}\right), f\left(x_{1}, \ldots, x_{k}\right)\right) \leq \sum_{i=1}^{k} \delta_{i} d\left(x_{i-1}, x_{i}\right),
$$

for all $x_{0}, \ldots, x_{k} \in X$, where $\delta_{1}, \ldots, \delta_{k}$ are positive constants such that $\delta_{1}+\ldots+\delta_{k} \in$ $(0,1)$. Then $f$ has a unique fixed point $x^{*} \in X$, that is, there exists a unique $x^{*} \in X$ such that $x^{*}=f\left(x^{*}, \ldots, x^{*}\right)$. Moreover, for any initial values $x_{0}, \ldots, x_{k-1} \in X$, the iterative sequence $\left\{x_{n}\right\}$ defined by (1) converges to $x^{*}$.

It is easy to show that for $k=1$, Theorem 1.2 reduces to the Banach contraction principle. So, Theorem 1.2 is a generalization of the Banach fixed point theorem.

In [13], Ćirić and Prešić generalized Theorem 1.2 as follows.

Theorem 1.3 (Ćirić and Prešić [13]) Let $(X, d)$ be a complete metric space, $k$ a positive integer and $f: X^{k} \rightarrow X$. Suppose that

$$
d\left(f\left(x_{0}, \ldots, x_{k-1}\right), f\left(x_{1}, \ldots, x_{k}\right)\right) \leq \lambda \max \left\{d\left(x_{0}, x_{1}\right), \ldots, d\left(x_{k-1}, x_{k}\right)\right\},
$$

for all $x_{0}, \ldots, x_{k} \in X$, where $\lambda \in(0,1)$ is a constant. Then $f$ has a unique fixed point $x^{*}$ $\in X$, that is, there exists a unique $x^{*} \in X$ such that $x^{*}=f\left(x^{*}, \ldots, x^{*}\right)$. Moreover, for any initial values $x_{0}, \ldots, x_{k-1} \in X$, the iterative sequence $\left\{x_{n}\right\}$ defined by (1) converges to $x^{*}$.

The applicability of the result due to Cirić and Prešić to the study of global asymptotic stability of the equilibrium for the nonlinear difference Equation (1) is revealed, for example, in the recent article [8].

Other generalizations were obtained by Păcurar in [20,21].

Theorem 1.4 (Păcurar [20]) Let $(X, d)$ be a complete metric space, $k$ a positive integer and $f: X^{k} \rightarrow X$. Suppose that

$$
d\left(f\left(x_{0}, \ldots, x_{k-1}\right), f\left(x_{1}, \ldots, x_{k}\right)\right) \leq a \sum_{i=0}^{k} d\left(x_{i}, f\left(x_{i}, \ldots, x_{i}\right)\right),
$$

for all $x_{0}, \ldots, x_{k} \in X$, where $a$ is a constant such that $0<a k(k+1)<1$. Then $f$ has a unique fixed point $x^{*} \in X$, that is, there exists a unique $x^{*} \in X$ such that $x^{*}=f\left(x^{*}, \ldots\right.$, $\left.x^{*}\right)$. Moreover, for any initial values $x_{0}, \ldots, x_{k-1} \in X$, the iterative sequence $\left\{x_{n}\right\}$ defined by (1) converges to $x^{*}$.

In the particular case $k=1$, from Theorem 1.4, we obtain Kannan's fixed point theorem for discontinuous mappings in [15].

Theorem 1.5 (Păcurar [21]) Let $(X, d)$ be a complete metric space, $k$ a positive integer and $f: X^{k} \rightarrow X$. Suppose that

$$
d\left(f\left(x_{0}, \ldots, x_{k-1}\right), f\left(x_{1}, \ldots, x_{k}\right)\right) \leq \sum_{i=1}^{k} \delta_{i} d\left(x_{i-1}, x_{i}\right)+M\left(x_{0}, x_{k}\right),
$$

for all $x_{0}, \ldots, x_{k} \in X$, where $\delta_{1}, \ldots, \delta_{k}$ are positive constants such that $\sum_{i=1}^{k} \delta_{i}<1$ and

$$
\begin{aligned}
& M\left(x_{0}, x_{k}\right)= \\
& L \min \left\{d\left(x_{0}, f\left(x_{0}, \ldots, x_{0}\right)\right), d\left(x_{k}, f\left(x_{k}, \ldots, x_{k}\right)\right), d\left(x_{0}, f\left(x_{k}, \ldots, x_{k}\right)\right), d\left(x_{k}, f\left(x_{0}, \ldots, x_{0}\right)\right),\right. \\
& \left.\quad d\left(x_{k}, f\left(x_{0}, \ldots, x_{k-1}\right)\right)\right\}
\end{aligned}
$$


with $L \geq 0$. Then $f$ has a unique fixed point $x^{*} \in X$, that is, there exists a unique $x^{*} \in$ $X$ such that $x^{*}=f\left(x^{*}, \ldots, x^{*}\right)$. Moreover, for any initial values $x_{0}, \ldots, x_{k-1} \in X$, the iterative sequence $\left\{x_{n}\right\}$ defined by (1) converges to $x^{*}$.

In the particular case $k=1$, the contractive condition (2) reduces to strict almost contraction (see [4-7]).

Note that these approaches are motivated by the currently increasing interest in the study of nonlinear difference equations which appear in many interesting examples from system theory, economics, inventory analysis, probability models for learning, approximate solutions of ordinary and partial differential equations just to mention a few [29-31]. We refer the reader to [32-34] for a detailed study of the theory of difference equations.

For other studies in this direction, we refer the reader to $[23,25,35,36]$.

In this article, we study the convergence of the iterative sequence (1) for more general classes of operators. Presented theorems extend and generalize many existing results in the literature including Theorems 1.1, 1.2, 1.4, and 1.5. We present also an application to a class of nonlinear difference matrix equations and we validate our results with numerical experiments.

\section{Main results}

In order to prove our main results we shall need the following lemmas.

Lemma 2.1 Let $k$ be a positive integer and $\alpha_{1}, \alpha_{2}, \ldots, \alpha_{k} \geq 0$ such that $\sum_{i=1}^{k} \alpha_{i}=\alpha<1$. If $\left\{\Delta_{n}\right\}$ is a sequence of positive numbers satisfying

$$
\Delta_{n+k} \leq \alpha_{1} \Delta_{n}+\alpha_{2} \Delta_{n+1}+\cdots+\alpha_{k} \Delta_{n+k-1}, \quad n \geq 1,
$$

then there exist $L \geq 0$ and $\tau \in(0,1)$ such that $\Delta_{n} \leq L \tau^{n}$ for all $n \geq 1$.

Lemma 2.2 Let $\left\{a_{n}\right\},\left\{b_{n}\right\}$ be two sequences of positive real numbers and $q \in(0,1)$ such that $a_{n+1} \leq q a_{n}+b_{n}, n \geq 0$ and $b_{n} \rightarrow 0$ as $n \rightarrow \infty$. Then $a_{n} \rightarrow 0$ as $n \rightarrow \infty$.

Let $\Theta$ be the set of functions $\theta:[0, \infty)^{4} \rightarrow[0, \infty)$ satisfying the following conditions:

(i) $\theta$ is continuous,

(ii) for all $t_{1}, t_{2}, t_{3}, t_{4} \in[0, \infty)$,

$$
\theta\left(t_{1}, t_{2}, t_{3}, t_{4}\right)=0 \Leftrightarrow t_{1} t_{2} t_{3} t_{4}=0 .
$$

Example 2.1 The following functions belong to $\Theta$ :

(1) $\theta\left(t_{1}, t_{2}, t_{3}, t_{4}\right)=L \min \left\{t_{1}, t_{2}, t_{3}, t_{4}\right\}, L>0 t_{1}, t_{2}, t_{3}, t_{4} \geq 0$.

(2) $\theta\left(t_{1}, t_{2}, t_{3}, t_{4}\right)=L \ln \left(1+t_{1} t_{2} t_{3} t_{4}\right), L>0 t_{1}, t_{2}, t_{3}, t_{4} \geq 0$.

(3) $\theta\left(t_{1}, t_{2}, t_{3}, t_{4}\right)=L \ln \left(1+t_{1}\right) \ln \left(1+t_{2}\right) \ln \left(1+t_{3}\right) \ln \left(1+t_{4}\right), L>0 t_{1}, t_{2}, t_{3}, t_{4} \geq 0$.

(4) $\theta\left(t_{1}, t_{2}, t_{3}, t_{4}\right)=L t_{1} t_{2} t_{3} t_{4}, L>0 t_{1}, t_{2}, t_{3}, t_{4} \geq 0$.

(5) $\theta\left(t_{1}, t_{2}, t_{3}, t_{4}\right)=L\left(e^{t_{1} t_{2} t_{3} t_{4}}-1\right), L>0 t_{1}, t_{2}, t_{3}, t_{4} \geq 0$.

Our first result is the following.

Theorem 2.1 Let $(X, d)$ be a complete metric space, $k$ a positive integer and $f: X^{k} \rightarrow$ $X$. Suppose that 


$$
\begin{aligned}
& d\left(f\left(x_{0}, \ldots, x_{k-1}\right), f\left(x_{1}, \ldots, x_{k}\right)\right) \leq \sum_{i=1}^{k} \delta_{i} d\left(x_{i-1}, x_{i}\right)+\delta_{k+1} \sum_{i=0}^{k} d\left(x_{i}, f\left(x_{i}, \ldots, x_{i}\right)\right) \\
& \quad+\theta\left(d\left(x_{0}, f\left(x_{0}, \ldots, x_{0}\right)\right), d\left(x_{k}, f\left(x_{k}, \ldots, x_{k}\right)\right), d\left(x_{0}, f\left(x_{k}, \ldots, x_{k}\right)\right), d\left(x_{k}, f\left(x_{0}, \ldots, x_{0}\right)\right)\right)
\end{aligned}
$$

for all $x_{0}, \ldots, x_{k} \in X$, where $\delta_{1}, \ldots, \delta_{k+1}$ are positive constants such that $2 A+\delta \in(0,1)$ with $A=\frac{k(k+1)}{2} \delta_{k+1}$ and $\delta=\sum_{i=1}^{k} \delta_{i}$. Then $f$ has a unique fixed point $x^{*} \in X$, that is, there exists a unique $x^{*} \in X$ such that $x^{*}=f\left(x^{*}, \ldots, x^{*}\right)$. Moreover, for any $z_{0} \in X$, the iterative sequence $\left\{z_{n}\right\}$ defined by

$$
z_{n+1}=f\left(z_{n}, \ldots, z_{n}\right), \quad n \geq 0
$$

converges to $x^{*}$.

Proof. Define the mapping $F: X \rightarrow X$ by

$$
F x=f(x, \ldots, x), \quad \text { for all } x \in X .
$$

Using (3), for all $x, y \in X$, we have

$$
\begin{aligned}
& d(F x, F y)=d(f(x, \ldots, x), f(y, \ldots, y)) \\
& \quad \leq d(f(x, \ldots, x), f(x, \ldots, x, y))+d(f(x, \ldots, x, y), f(x, \ldots, x, y, y)) \\
& \quad+\cdots+d(f(x, y, \ldots, y), f(y, \ldots, y)) \\
& \quad \leq\left[\delta_{k} d(x, y)+\delta_{k-1} d(x, y)+\cdots+\delta_{1} d(x, y)\right]+(1+\cdots+k) \delta_{k+1}[d(x, F x)+d(y, F y)] \\
& \quad+k \theta(d(x, F x), d(y, F y), d(x, F y), d(y, F x)) .
\end{aligned}
$$

Thus, we have

$$
d(F x, F y) \leq\left(\sum_{i=1}^{k} \delta_{i}\right) d(x, y)+\frac{k(k+1)}{2} \delta_{k+1}[d(x, F x)+d(y, F y)]+M(x, y)
$$

where

$$
M(x, y)=k \theta(d(x, F x), d(y, F y), d(x, F y), d(y, F x))
$$

Now, let $z_{0}$ be an arbitrary element of $X$. Define the sequence $\left\{z_{n}\right\}$ by

$$
z_{n}=F z_{n-1}=f\left(z_{n-1}, \ldots, z_{n-1}\right), \quad n \geq 1 .
$$

Using (4), we have

$$
\begin{aligned}
d\left(z_{n+1}, z_{n}\right)=d\left(F z_{n}, F z_{n-1}\right) & \leq\left(\sum_{i=1}^{k} \delta_{i}\right) d\left(z_{n}, z_{n-1}\right)+\frac{k(k+1)}{2} \delta_{k+1}\left[d\left(z_{n}, z_{n+1}\right)+d\left(z_{n-1}, z_{n}\right)\right] \\
& +M\left(z_{n}, z_{n-1}\right) .
\end{aligned}
$$

On the other hand, from the property (ii) of the function $\theta$, we have

$$
M\left(z_{n}, z_{n-1}\right)=k \theta\left(d\left(z_{n}, z_{n+1}\right), d\left(z_{n-1}, z_{n}\right), 0, d\left(z_{n-1}, z_{n+1}\right)\right)=0 .
$$

Then we get

$$
d\left(z_{n+1}, z_{n}\right) \leq \delta d\left(z_{n}, z_{n-1}\right)+\frac{k(k+1)}{2} \delta_{k+1}\left[d\left(z_{n}, z_{n+1}\right)+d\left(z_{n-1}, z_{n}\right)\right]
$$


for all $n=1,2, \ldots$. This implies that

$$
d\left(z_{n+1}, z_{n}\right) \leq \frac{A+\delta}{1-A} d\left(z_{n}, z_{n-1}\right)
$$

for all $n=1,2, \ldots$. Since we have $2 A+\delta \in(0,1)$, then $\left\{z_{n}\right\}$ is a Cauchy sequence in $(X$, $d)$. Now, since $(X, d)$ is complete, there exists $x^{*} \in X$ such that $z_{n} \rightarrow x^{*}$ as $n \rightarrow \infty$. We shall prove that $x^{*}$ is a fixed point of $F$, that is, $x^{*}=F x^{*}$. Using (4), we have

$$
\begin{aligned}
& d\left(x^{*}, F x^{*}\right) \leq d\left(x^{*}, z_{n+1}\right)+d\left(F z_{n}, F x^{*}\right) \\
& \leq d\left(x^{*}, z_{n+1}\right)+\left(\sum_{i=1}^{k} \delta_{i}\right) d\left(z_{n}, x^{*}\right)+\frac{k(k+1)}{2} \delta_{k+1}\left[d\left(z_{n}, z_{n+1}\right)+d\left(x^{*}, F x^{*}\right)\right]+M\left(z_{n}, x^{*}\right),
\end{aligned}
$$

where

$$
M\left(z_{n}, x^{*}\right)=k \theta\left(d\left(z_{n}, z_{n+1}\right), d\left(x^{*}, F x^{*}\right), d\left(z_{n}, F x^{*}\right), d\left(x^{*}, z_{n+1}\right)\right) .
$$

Thus we have

$$
(1-A) d\left(x^{*}, F x^{*}\right) \leq d\left(x^{*}, z_{n+1}\right)+\delta d\left(z_{n}, x^{*}\right)+A d\left(z_{n}, z_{n+1}\right)+M\left(z_{n}, x^{*}\right) .
$$

Letting $n \rightarrow \infty$ in the above inequality, and using the properties (i) and (ii) of $\theta$, we obtain

$$
(1-A) d\left(x^{*}, F x^{*}\right) \leq 0,
$$

which implies (since $1-A>0)$ that $x^{*}=F x^{*}=f\left(x^{*}, \ldots, x^{*}\right)$.

Now, we shall prove that $x^{*}$ is the unique fixed point of $F$. Suppose that $y^{*} \in X$ is another fixed point of $F$, that is, $y^{*}=F y^{*}=f\left(y^{*}, \ldots, y^{*}\right)$. Using (4), we have

$$
\begin{aligned}
& d\left(x^{*}, y^{*}\right)=d\left(F x^{*}, F y^{*}\right) \\
& \leq \delta d\left(x^{*}, \gamma^{*}\right)+\frac{k(k+1)}{2} \delta_{k+1}\left[d\left(x^{*}, F x^{*}\right)+d\left(y^{*}, F \gamma^{*}\right)\right]+M\left(x^{*}, y^{*}\right) \\
& =\delta d\left(x^{*}, y^{*}\right)+M\left(x^{*}, \gamma^{*}\right) .
\end{aligned}
$$

On the other hand, we have

$$
M\left(x^{*}, y^{*}\right)=k \theta\left(d\left(x^{*}, F x^{*}\right), d\left(y^{*}, F y^{*}\right), d\left(x^{*}, F y^{*}\right), d\left(y^{*}, F x^{*}\right)\right)=k \theta\left(0,0, d\left(x^{*}, y^{*}\right), d\left(y^{*}, x^{*}\right)\right)=0 .
$$

Then we get

$$
(1-\delta) d\left(x^{*}, \gamma^{*}\right) \leq 0,
$$

which implies (since $\delta<1)$ that $x^{*}=y^{*}$.

Theorem 2.2 Let $(X, d)$ be a complete metric space, $k$ a positive integer and $f: X^{k} \rightarrow$ $X$. Suppose that

$$
\begin{aligned}
& d\left(f\left(x_{0}, \ldots, x_{k-1}\right), f\left(x_{1}, \ldots, x_{k}\right)\right) \leq \sum_{i=1}^{k} \delta_{i} d\left(x_{i-1}, x_{i}\right) \\
& +B \min \left\{d\left(x_{k}, f\left(x_{0}, \ldots, x_{k-1}\right)\right), \theta\left(d\left(x_{0}, f\left(x_{0}, \ldots, x_{0}\right)\right), d\left(x_{k}, f\left(x_{k}, \ldots, x_{k}\right)\right),\right.\right. \\
& \left.\left.d\left(x_{0}, f\left(x_{k}, \ldots, x_{k}\right)\right), d\left(x_{k}, f\left(x_{0}, \ldots, x_{0}\right)\right)\right)\right\}
\end{aligned}
$$


for all $x_{0}, \ldots, x_{k} \in X$, where $\delta_{1}, \ldots, \delta_{k}$ are positive constants such that $\delta \in(0,1)$ with $\delta=\sum_{i=1}^{k} \delta_{i}$, and $B \geq 0$. Then

(a) there exists a unique $x^{*} \in X$ such that $x^{*}=f\left(x^{*}, \ldots, x^{*}\right)$;

(b) the sequence $\left\{x_{n}\right\}$ defined by

$$
x_{n+1}=f\left(x_{n-k+1}, \ldots, x_{n}\right), \quad n=k-1, k, k+1, \ldots
$$

converges to $x^{*}$ for any $x_{0}, \ldots, x_{k-1} \in X$.

Proof. Applying Theorem 2.1 with $\delta_{k+1}=0$, and remarking that $B \theta \in \Theta$, we obtain immediately (a). Now, we shall prove (b). Let $x_{0}, \ldots, x_{k-1} \in X$ and $x_{n}=f\left(x_{n-k}, \ldots, x_{n-1}\right), n \geq$ $k$. Then by (5), the property (ii) of $\theta$ and since $x^{*}=F x^{*}=f\left(x^{*}, \ldots, x^{*}\right)$, we have

$$
\begin{aligned}
& d\left(x_{k}, x^{*}\right)=d\left(f\left(x_{0}, \ldots, x_{k-1}\right), f\left(x^{*}, \ldots, x^{*}\right)\right) \\
& \quad \leq d\left(f\left(x_{0}, \ldots, x_{k-1}\right), f\left(x_{1}, \ldots, x_{k-1}, x^{*}\right)\right) \\
& \quad+d\left(f\left(x_{1}, \ldots, x_{k-1}, x^{*}\right), f\left(x_{2}, \ldots, x_{k-1}, x^{*}, x^{*}\right)\right) \\
& \quad+\cdots \\
& \quad+d\left(f\left(x_{k-1}, x^{*}, \ldots, x^{*}\right), f\left(x^{*}, \ldots, x^{*}\right)\right) \\
& \quad \leq \delta_{1} d\left(x_{0}, x_{1}\right)+\left(\delta_{1}+\delta_{2}\right) d\left(x_{1}, x_{2}\right)+\cdots+\left(\delta_{1}+\cdots+\delta_{k-1}\right) d\left(x_{k-2}, x_{k-1}\right)+\delta d\left(x_{k-1}, x^{*}\right) .
\end{aligned}
$$

Since $k$ is a fixed positive integer, then we may denote

$$
E_{0}=\delta_{1} d\left(x_{0}, x_{1}\right)+\left(\delta_{1}+\delta_{2}\right) d\left(x_{1}, x_{2}\right)+\cdots+\left(\delta_{1}+\cdots+\delta_{k-1}\right) d\left(x_{k-2}, x_{k-1}\right) .
$$

Then we get

$$
d\left(x_{k}, x^{*}\right) \leq E_{0}+\delta d\left(x_{k-1}, x^{*}\right) .
$$

Similarly we get that

$$
d\left(x_{k+1}, x^{*}\right) \leq \delta_{1} d\left(x_{1}, x_{2}\right)+\left(\delta_{1}+\delta_{2}\right) d\left(x_{2}, x_{3}\right)+\cdots+\left(\delta_{1}+\cdots+\delta_{k-1}\right) d\left(x_{k-1}, x_{k}\right)+\delta d\left(x_{k}, x^{*}\right) .
$$

Denoting

$$
E_{1}=\delta_{1} d\left(x_{1}, x_{2}\right)+\left(\delta_{1}+\delta_{2}\right) d\left(x_{2}, x_{3}\right)+\cdots+\left(\delta_{1}+\cdots+\delta_{k-1}\right) d\left(x_{k-1}, x_{k}\right),
$$

we get

$$
d\left(x_{k+1}, x^{*}\right) \leq E_{1}+\delta d\left(x_{k}, x^{*}\right) .
$$

Continuing this process, for $n \geq k$, we obtain

$$
\begin{aligned}
& d\left(x_{n}, x^{*}\right) \leq \delta_{1} d\left(x_{n-k}, x_{n-k+1}\right)+\left(\delta_{1}+\delta_{2}\right) d\left(x_{n-k+1}, x_{n-k+2}\right)+\cdots+\left(\delta_{1}+\cdots+\delta_{k-1}\right) d\left(x_{n-2}, x_{n-1}\right) \\
& +\delta d\left(x_{n-1}, x^{*}\right) .
\end{aligned}
$$

Denoting

$$
E_{n-k}=\delta_{1} d\left(x_{n-k}, x_{n-k+1}\right)+\left(\delta_{1}+\delta_{2}\right) d\left(x_{n-k+1}, x_{n-k+2}\right)+\cdots+\left(\delta_{1}+\cdots+\delta_{k-1}\right) d\left(x_{n-2}, x_{n-1}\right),
$$

the above inequality becomes

$$
d\left(x_{n}, x^{*}\right) \leq \delta d\left(x_{n-1}, x^{*}\right)+E_{n-k}, \quad n \geq k .
$$

Now, we shall prove that the sequence $\left\{E_{n}\right\}$ given by

$$
E_{n}=\delta_{1} d\left(x_{n}, x_{n+1}\right)+\left(\delta_{1}+\delta_{2}\right) d\left(x_{n+1}, x_{n+2}\right)+\cdots+\left(\delta_{1}+\cdots+\delta_{k-1}\right) d\left(x_{n+k-2}, x_{n+k-1}\right),
$$


converges to 0 as $n \rightarrow \infty$.

For $n \geq k$, from (5), we have

$$
\begin{aligned}
& d\left(x_{n}, x_{n+1}\right)=d\left(f\left(x_{n-k}, \ldots, x_{n-1}\right), f\left(x_{n-k+1}, \ldots, x_{n}\right)\right) \\
& \leq \delta_{1} d\left(x_{n-k}, x_{n-k+1}\right)+\delta_{2} d\left(x_{n-k+1}, x_{n-k+2}\right)+\ldots+\delta_{k} d\left(x_{n-1}, x_{n}\right) \\
& +B \min \left\{d\left(x_{n}, f\left(x_{n-k}, \ldots, x_{n-1}\right), \theta\left(d\left(x_{n-k}, F\left(x_{n-k}\right)\right), d\left(x_{n}, F x_{n}\right), d\left(x_{n-k}, F x_{n}\right), d\left(x_{n}, F x_{n-k}\right)\right)\right\} .\right.
\end{aligned}
$$

As $d\left(x_{n}, f\left(x_{n-k}, \ldots, x_{n-1}\right)=0\right.$, the above inequality leads to

$$
d\left(x_{n}, x_{n+1}\right) \leq \delta_{1} d\left(x_{n-k}, x_{n-k+1}\right)+\delta_{2} d\left(x_{n-k+1}, x_{n-k+2}\right)+\cdots+\delta_{k} d\left(x_{n-1}, x_{n}\right) .
$$

According to Lemma 2.1, this implies the existence of $\tau \in(0,1)$ and $L \geq 0$ such that

$$
d\left(x_{n}, x_{n+1}\right) \leq L \tau^{n}, \quad \text { for all } n \geq 1 .
$$

Now, $E_{n}$ is a finite sum of sequences converging to 0 , so it is convergent to 0 .

Finally, using (7) and applying Lemma 2.2 with $a_{n}=d\left(x_{n}, x^{*}\right)$ and $b_{n}=E_{n+1-k}$, we get that $d\left(x_{n}, x^{*}\right) \rightarrow 0$ as $n \rightarrow \infty$, that is, the iterative sequence $\left\{x_{n}\right\}$ converges to the unique fixed point of $f$

Remark 2.1 In the particular case $\theta\left(t_{1}, t_{2}, t_{3}, t_{4}\right)=\min \left\{t_{1}, t_{2}, t_{3}, t_{4}\right\}$, from Theorem 2.2 we obtain Păcurar's result (see Theorem 1.5).

Now, we shall prove the following result.

Theorem 2.3 Let $(X, d)$ be a complete metric space, $k$ a positive integer and $f: X^{k} \rightarrow$ $X$.

Suppose that

$$
\begin{aligned}
& d\left(f\left(x_{0}, \ldots, x_{k-1}\right), f\left(x_{1}, \ldots, x_{k}\right)\right) \leq a \sum_{i=0}^{k} d\left(x_{i}, f\left(x_{i}, \ldots, x_{i}\right)\right) \\
& +\theta\left(d\left(x_{0}, f\left(x_{0}, \ldots, x_{0}\right)\right), d\left(x_{k}, f\left(x_{k}, \ldots, x_{k}\right)\right), d\left(x_{0}, f\left(x_{k}, \ldots, x_{k}\right)\right), d\left(x_{k}, f\left(x_{0}, \ldots, x_{0}\right)\right)\right)
\end{aligned}
$$

for all $x_{0}, \ldots, x_{k} \in X$, where $a$ is a positive constant such that $A \in(0,1 / 2)$ with $A=\frac{k(k+1)}{2} a$. Then

(a) there exists a unique $x^{*} \in X$ such that $x^{*}=f\left(x^{*}, \ldots, x^{*}\right)$;

(b) the sequence $\left\{x_{n}\right\}$ defined by

$$
x_{n+1}=f\left(x_{n-k+1}, \ldots, x_{n}\right), \quad n=k-1, k, k+1 \ldots
$$

converges to $x^{*}$ for any $x_{0}, \ldots, x_{k-1} \in X$, with a rate estimated by

$$
d\left(x_{n+1}, x^{*}\right) \leq \frac{a L}{1-A} M \tau^{n}, \quad n \geq k,
$$

where $L \geq 0, \tau \in(0,1)$ and $M=\tau^{1-k}+2 \tau^{2-k}+\ldots+k$.

Proof. (a) follows immediately from Theorem 2.1 with $\delta=0$ and $\delta_{k+1}=a$. Now, we shall prove (b). Let $x_{0}, \ldots, x_{k-1} \in X$ and $x_{n}=f\left(x_{n-k}, \ldots, x_{n-1}\right), n \geq k$. Then by (8), the property (ii) of $\theta$ and since $x^{*}=F x^{*}=f\left(x^{*}, \ldots, x^{*}\right)$, we have 


$$
\begin{aligned}
& d\left(x_{k}, x^{*}\right)=d\left(f\left(x_{0}, \ldots, x_{k-1}\right), f\left(x^{*}, \ldots, x^{*}\right)\right) \\
& \quad \leq d\left(f\left(x_{0}, \ldots, x_{k-1}\right), f\left(x_{1}, \ldots, x_{k-1}, x^{*}\right)\right) \\
& \quad+d\left(f\left(x_{1}, \ldots, x_{k-1}, x^{*}\right), f\left(x_{2}, \ldots, x_{k-1}, x^{*}, x^{*}\right)\right) \\
& \quad+\cdots \\
& \quad+d\left(f\left(x_{k-1}, x^{*}, \ldots, x^{*}\right), f\left(x^{*}, \ldots, x^{*}\right)\right) \\
& \quad \leq a d\left(x_{0}, F x_{0}\right)+2 a d\left(x_{1}, F x_{1}\right)+\cdots+k a d\left(x_{k-1}, F x_{k-1}\right) .
\end{aligned}
$$

Using (4), for all $i=0,1, \ldots, k-1$, we get

$$
\begin{aligned}
& d\left(x_{i}, F x_{i}\right) \leq d\left(x_{i}, x^{*}\right)+d\left(F x_{i}\right) \\
& \quad \leq d\left(x_{i}, x^{*}\right)+A d\left(x_{i}, F x_{i}\right)+k \theta\left(0, d\left(x_{i}, F x_{i}\right), d\left(x^{*}, F x_{i}\right), d\left(x_{i}, F x^{*}\right)\right) \\
& \quad=d\left(x^{*}, x_{i}\right)+A d\left(x_{i}, F x_{i}\right) .
\end{aligned}
$$

This implies that

$$
d\left(x_{i}, F x_{i}\right) \leq \frac{1}{1-A} d\left(x_{i}, x^{*}\right), \quad i=0,1, \ldots, k-1 .
$$

Now, combining (12) with (11), we obtain

$$
d\left(x_{k}, x^{*}\right) \leq \frac{a}{1-A} d\left(x_{0}, x^{*}\right)+\frac{2 a}{1-A} d\left(x_{1}, x^{*}\right)+\cdots+\frac{k a}{1-A} d\left(x_{k-1}, x^{*}\right) .
$$

Similarly, one can show that

$$
d\left(x_{n}, x^{*}\right) \leq \frac{a}{1-A} d\left(x_{n-k}, x^{*}\right)+\frac{2 a}{1-A} d\left(x_{n-k+1}, x^{*}\right)+\cdots+\frac{k a}{1-A} d\left(x_{n-1}, x^{*}\right), \quad n \geq k .
$$

This implies that

$$
d\left(x_{p+k}, x^{*}\right) \leq \frac{a}{1-A} d\left(x_{p}, x^{*}\right)+\frac{2 a}{1-A} d\left(x_{p+1}, x^{*}\right)+\cdots+\frac{k a}{1-A} d\left(x_{p+k-1}, x^{*}\right), \quad p \geq 0 .
$$

Define the sequence $\left\{\Delta_{p}\right\}$ by

$$
\Delta_{p}=d\left(x_{p}, x^{*}\right), \text { for all } p \geq 0 .
$$

We get that

$$
\Delta_{p+k} \leq \frac{a}{1-A} \Delta_{p}+\frac{2 a}{1-A} \Delta_{p+1}+\cdots+\frac{k a}{1-A} \Delta_{p+k-1}, \quad p \geq 0 .
$$

Since $\sum_{i=1}^{k} \frac{i a}{1-A}=\frac{A}{1-A} \in(0,1)$, we can apply Lemma 2.1 to deduce that there exist $L \geq 0$ and $\tau \in(0,1)$ such that

$$
\Delta_{p} \leq L \tau^{p}, \quad p \geq 1
$$

This implies that $\Delta_{p} \rightarrow 0$ as $p \rightarrow \infty$, that is, $x_{p} \rightarrow x^{*}$ as $p \rightarrow \infty$. Finally, (10) follows from (14) and (13).

Remark 2.2 Many results can be derived from our Theorems 2.1, 2.2 and 2.3 with respect to particular choices of $\theta$ (see Example 2.1).

Remark 2.3 Clearly, Theorem 1.4 of Păcurar is a particular case of our Theorem 2.3. 


\section{Application: convergence of the recursive matrix sequence}

$$
\mathbf{X}_{\mathbf{n}+1}=\mathbf{Q}+\mathbf{A}^{*} \mathbf{X}_{\mathbf{n}-1}^{\alpha} \mathbf{A}+\mathbf{B}^{*} \mathbf{X}_{\mathbf{n}}^{\beta} \mathbf{B}
$$

In the last few years there has been a constantly increasing interest in developing the theory and numerical approaches for Hermitian positive definite (HPD) solutions to different classes of nonlinear matrix equations (see [37-41]). In this section, basing on Theorem 1.3 of Ćirić and Prešić, we shall study the nonlinear matrix difference equation

$$
X_{n+1}=Q+A^{*} X_{n-1}^{\alpha} A+B^{*} X_{n}^{\beta} B,
$$

where $Q$ is an $N \times N$ positive definite matrix, $A$ and $B$ are arbitrary $N \times N$ matrices, $\alpha$ and $\beta$ are real numbers. Here, $A^{*}$ denotes the conjugate transpose of the matrix $A$.

We first review the Thompson metric on the open convex cone $P(N)(N \geq 2)$, the set of all $N \times N$ Hermitian positive definite matrices. We endow $P(N)$ with the Thompson metric defined by

$$
d(A, B)=\max \{\log M(A / B), \log M(B / A)\},
$$

where $M(A / B)=\inf \{\lambda>0: A \leq \lambda B\}=\lambda^{+}\left(B^{-1 / 2} A B^{-1 / 2}\right)$, the maximal eigenvalue of $B^{-1 /}$ ${ }^{2} A B^{-1 / 2}$. Here, $X \leq Y$ means that $Y-X$ is positive semi-definite and $X<Y$ means that $Y$ - $X$ is positive definite. Thompson [42] has proved that $P(n)$ is a complete metric space with respect to the Thompson metric $d$ and $d(A, B)=\left|\log \left(A^{-1 / 2} B A^{-1 / 2}\right)\right|$, where $|\cdot|$ stands for the spectral norm. The Thompson metric exists on any open normal convex cones of real Banach spaces; in particular, the open convex cone of positive definite operators of a Hilbert space. It is invariant under the matrix inversion and congruence transformations, that is,

$$
d(A, B)=d\left(A^{-1}, B^{-1}\right)=d\left(M A M^{*}, M B M^{*}\right)
$$

for any nonsingular matrix $M$. The other useful result is the nonpositive curvature property of the Thompson metric, that is,

$$
d\left(X^{r}, Y^{r}\right) \leq r d(X, Y), \quad r \in[0,1] .
$$

By the invariant properties of the metric, we then have

$$
d\left(M X^{r} M^{*}, M Y^{r} M^{*}\right) \leq|r| d(X, Y), \quad r \in[-1,1]
$$

for any $X, Y \in P(N)$ and nonsingular matrix $M$.

Lemma 3.1 [40] For all $A, B, C, D \in P(N)$, we have

$$
d(A+B, C+D) \leq \max \{d(A, C), d(B, D)\} .
$$

In particular,

$$
d(A+B, A+C) \leq d(B, C) .
$$

\subsection{A convergence result}

We shall prove the following convergence result. 
Theorem 3.1 Suppose that $\lambda=\max \{|\alpha|,|\beta|\} \in(0,1)$. Then

(i) Equation (15) has a unique equilibrium point in $P(N)$, that is, there exists a unique $U \in P(N)$ such that

$$
U=Q+A^{*} U^{\alpha} A+B^{*} U^{\beta} B ;
$$

(ii) for any $X_{0}, X_{1}>0$, the iterative sequence $\left\{X_{n}\right\}$ defined by (15) converges to $U$.

Proof. Define the mapping $f: P(N) \times P(N) \rightarrow P(N)$ by

$$
f(X, Y)=Q+A^{*} X^{\alpha} A+B^{*} Y^{\beta} B, \quad X, Y \in P(N) .
$$

Using Lemma 3.1 and properties (16)-(18), for all $X, Y, Z \in P(N)$, we have

$$
\begin{aligned}
& d(f(X, Y), f(Y, Z))=d\left(Q+A^{*} X^{\alpha} A+B^{*} Y^{\beta} B, Q+A^{*} Y^{\alpha} A+B^{*} Z^{\beta} B\right) \\
& \quad \leq d\left(A^{*} X^{\alpha} A+B^{*} Y^{\beta} B, A^{*} Y^{\alpha} A+B^{*} Z^{\beta} B\right) \\
& \quad \leq \max \left\{d\left(A^{*} X^{\alpha} A, A^{*} Y^{\alpha} A\right), d\left(B^{*} Y^{\beta} B, B^{*} Z^{\beta} B\right)\right\} \\
& \quad \leq \max \{|\alpha| d(X, Y),|\beta| d(Y, Z)\} \\
& \quad \leq \max \{|\alpha|,|\beta|\} \max \{d(x, Y), d(Y, Z)\} \\
& \quad=\lambda \max \{d(x, Y), d(Y, Z)\} .
\end{aligned}
$$

Thus we proved that

$$
d(f(X, Y), f(Y, Z)) \leq \lambda \max \{d(X, Y), d(Y, Z)\}
$$

for all $X, Y, Z \in P(N)$. Since $\lambda \in(0,1)$, (i) and (ii) follow immediately from Theorem 1.3 .

\subsection{Numerical experiments}

All programs are written in MATLAB version 7.1.

We consider the iterative sequence $\left\{X_{n}\right\}$ defined by

$$
X_{n+1}=Q+A^{*} X_{n-1}^{1 / 2} A+B^{*} X_{n}^{1 / 3} B, \quad X_{0}, X_{1}>0,
$$

where

$$
A=\left(\begin{array}{lll}
0.306 & 0.6894 & 0.6093 \\
0.2514 & 0.4285 & 0.7642 \\
0.0222 & 0.0987 & 0.8519
\end{array}\right), \quad B=\left(\begin{array}{ccc}
0.9529 & 0.645 & 0.4801 \\
0.441 & 0.1993 & 0.9823 \\
0.9712 & 0.0052 & 0.92
\end{array}\right)
$$

and

$$
X_{0}=\left(\begin{array}{lll}
1 & 0 & 0 \\
0 & 1 & 0 \\
0 & 0 & 1
\end{array}\right), \quad X_{1}=Q=\left(\begin{array}{rrr}
10 & 3.85 & -3.85 \\
3.85 & 10 & 3.92 \\
-3.85 & 3.92 & 10
\end{array}\right) .
$$




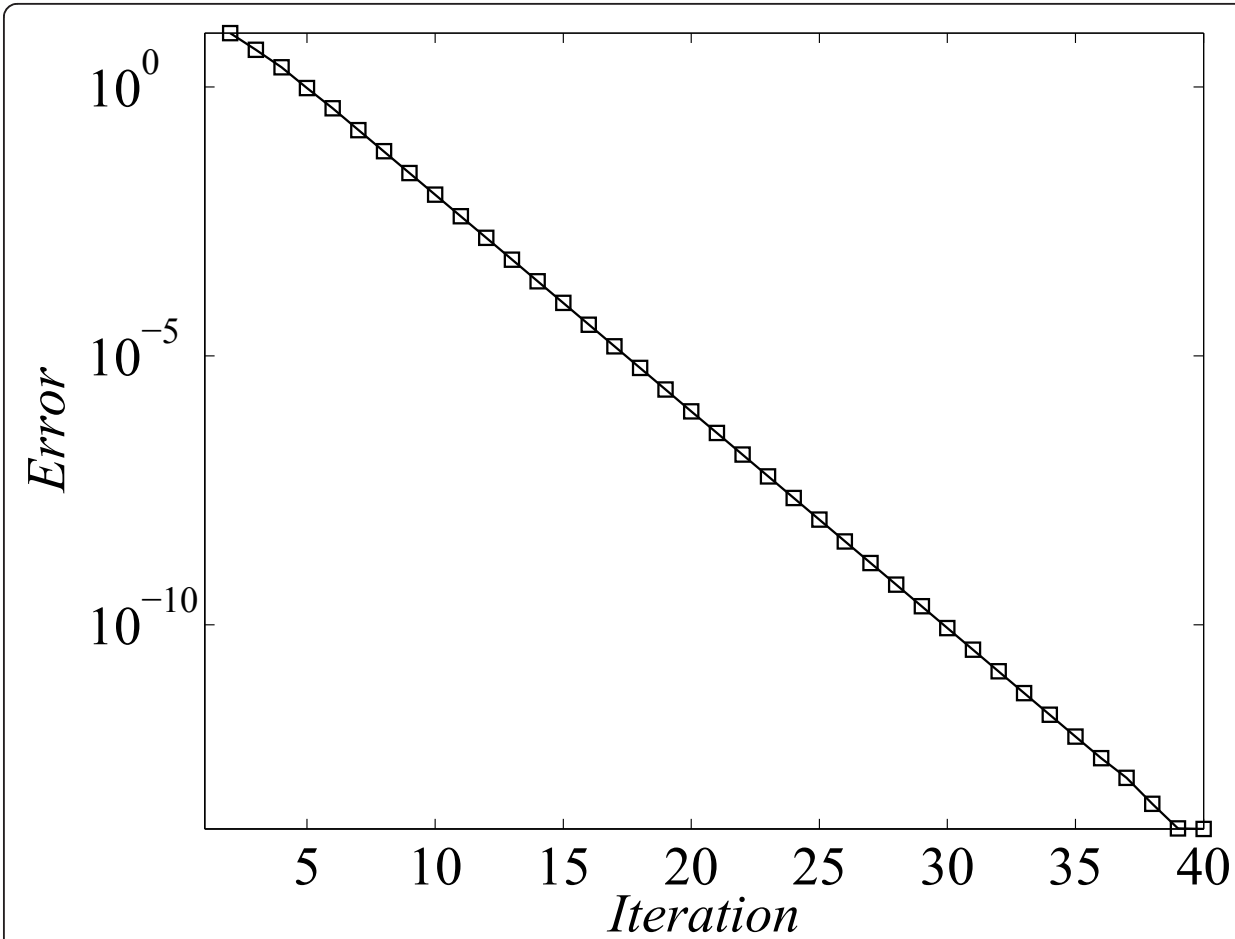

Figure 1 Convergence history for Equation (19).

It is clear that from our Theorem 3.1, Eq.(19) has a unique equilibrium point $U \in P$ (3). We denote by $R_{m}(m \geq 1)$ the residual error at the iteration $m$, that is,

$$
R_{m}=\left\|X_{m+1}-\left(Q+A^{*} X_{m+1}^{1 / 2} A+B^{*} X_{m+1}^{1 / 3} B\right)\right\|,
$$

where $|\cdot|$ is the spectral norm.

After 40 iterations, we obtain

$$
U \simeq X_{40}=\left(\begin{array}{lll}
17.22 & 7.559 & 4.429 \\
7.559 & 14.55 & 10.38 \\
4.429 & 10.38 & 26.56
\end{array}\right)
$$

with residual error

$$
R_{40}=1.624 \times 10^{-14}
$$

The convergence history of the algorithm (19) is given by Figure 1.

\section{Author details}

${ }^{1}$ Department of Mathematics and Statistics, College of Science, Sultan Qaboos University, Al-Khod, Post Box 36, PCode 123, Muscat, Sultanate of Oman 2Ecole Supérieure des Sciences et Techniques de Tunis, 5, Avenue Taha Hussein-Tunis, B.P. 56, Bab Menara-1008, Tunisie ${ }^{3}$ Department of Mathematics, King Saud University, Riyadh, Saudi Arabia

\section{Authors' contributions}

All authors contributed equally and significantly in writing this paper. All authors read and approved the final manuscript.

\section{Competing interests}

The authors declare that they have no competing interests. 


\section{References}

1. Banach, S: Sur les opérations dans les ensembles abstraits et leur application aux équations intégrales. Fund Math. 3, 133-181 (1922)

2. Agarwal, RP, Meehan, M, O'Regan, D: Fixed Point Theory and Applications. Cambridge University Press, Cambridge (2001)

3. Azam, A, Arshad, M, Beg, l: Fixed points of fuzzy contractive and fuzzy locally contractive maps. Chaos Solitons Fract. 42(5):2836-2841 (2009). doi:10.1016/j.chaos.2009.04.026

4. Babu, GVR, Sandhya, ML, Kameswari, MVR: A note on a fixed point theorem of Berinde on weak contractions. Carpathian J Math. 24, 8-12 (2008)

5. Berinde, V: On the approximation of fixed points of weak contractive mappings. Carpathian J Math. 19(1):7-22 (2003)

6. Berinde, V: Approximating fixed points of weak contractions using the Picard iteration. Nonlinear Anal Forum. 9, 43-53 (2004)

7. Berinde, V: Iterative Approximation of Fixed Points. Lecture Notes in Mathematics. Springer, Berlin (2007). 1912

8. Chen, YZ: A Prešić type contractive condition and its applications. Nonlinear Anal. 71, 2012-2017 (2009). doi:10.1016/j. na.2009.01.041

9. Ćirić, LB: Generalized contractions and fixed point theorems. Publ L'Inst Math. 12(26):19-26 (1971)

10. Ćirić, LB: On contraction type mappings. Math Balkanica. 1, 52-57 (1971)

11. Ćirić, LB: On a family of contractive maps and fixed points. Publ L'Inst Math. 17, 45-51 (1974)

12. Ćirić, LB: Some new results for Banach contractions and Edelstein contractive mappings on fuzzy metric spaces. Chaos Solitons Fract. 42(1):146-154 (2009). doi:10.1016/j.chaos.2008.11.010

13. Ćirić, LB, Prešić, SB: On Presic type generalisation of Banach contraction mapping principle. Acta Math Univ Com.

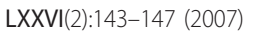

14. Imdad, M, Ali, J, Tanveer, M: Coincidence and common fixed point theorems for nonlinear contractions in Menger PM spaces. Chaos Solitons Fract. 42(5):3121-3129 (2009). doi:10.1016/j.chaos.2009.04.017

15. Kannan, R: Some results on fixed points. Bull Calcutta Math Soc. 60, 71-76 (1968)

16. Khan, MS, Swaleh, M, Sessa, S: Fixed point theorems by altering distances between the points. Bull Aust Math Soc. 30 , 1-9 (1984). doi:10.1017/S0004972700001659

17. Meir, A, Keeler, E: A theorem on contraction mappings. J Math Anal Appl. 28, 326-329 (1969). doi:10.1016/0022-247X (69) $90031-6$

18. Miheț, D: Fixed point theorems in probabilistic metric spaces. Chaos Solitons Fract. 41(2):1014-1019 (2009). doi:10.1016/ j.chaos.2008.04.030

19. Nadler, SB Jr: Multi-valued contraction mappings. Pac J Math. 30, 475-488 (1969)

20. Păcurar, M: Approximating common fixed points of Presić-Kannan type operators by a multi-step iterative method. An Șt Univ Ovidius Constanța. 17(1):153-168 (2009)

21. Păcurar, M: Fixed points of almost Persić operators by a k-step iterative method. An Ştiinț Univ Al I. Cuza laşi. Mat (N.S.) Tomul. LVII (2011)

22. Prešić, SB: Sur une classe d'inéquations aux differences finies et sur la convergence de certaines suites. Pub de l'Inst Math Belgrade. 5(19):75-78 (1965)

23. Rao, KPR, Kishore, GNV, Mustaq Ali, Md: A generalization of the Banach contraction principle of Presic type for three maps. Math Sci. 3(3):273-280 (2009)

24. Rhoades, BE: A comparison of various definitions of contractive mappings. Trans Am Math Soc. 226, 257-290 (1977)

25. Rus, IA: Generalized Contractions and Applications. Cluj University Press, Cluj-Napoca (2001)

26. Smart, DR: Fixed Point Theorems. Cambridge University Press, Cambridge (1974)

27. Suzuki, T: A generalized Banach contraction principle which characterizes metric completeness. Proc Am Math Soc. 136, 1861-1869 (2008)

28. Vetro, F: On approximating curves associated with nonexpansive mappings. Carpathian J Math. 27(1):142-147 (2011)

29. Godunov, SK, Ryabenku, VS: Difference Schemes. North-Holland, Amsterdam (1987)

30. Goldberg, S: Introduction to Difference Equations. Wiley, New York (1958)

31. Johnson, RM: Theory and Applications of Linear Differential and Difference Equations. Wiley, New York (1984)

32. Agarwal, RP: Difference Equations and Inequalities. Marcel Dekker, New York (1992)

33. Kelley, WG, Peterson, A: Diference Equations. Academic press, New York (1990)

34. Lakshmikautham, V, Frigiante, D: Theory of Difference Equations. Academic press, New York (1990)

35. Rus, IA: An iterative method for the solution of the equation $x=f(x, \ldots, x)$. Rev Anal Numer Theory Approx. 10(1):95-100 (1981)

36. Rus, IA: An Abstract Point of View in the Nonlinar Difference Equations. pp. 272-276. Editura Carpatica, Cluj-Napoca (1999)

37. Dehgham, M, Hajarian, M: An efficient algorithm for solving general coupled matrix equations and its application. Math Comput Model. 51, 1118-1134 (2010). doi:10.1016/j.mcm.2009.12.022

38. Duan, $X$, Liao, A: On Hermitian positive definite solution of the matrix equation $\sum_{i=1}^{m} A_{i}^{*} X^{r} A_{i}=Q$. J Comput Appl Math. 229, 27-36 (2009). doi:10.1016/j.cam.2008.10.018

39. Liao, A, Yao, G, Duan, X: Thompson metric method for solving a class of nonlinear matrix equation. Appl Math Comput. 216, 1831-1836 (2010). doi:10.1016/j.amc.2009.12.022

40. Lim, Y: Solving the nonlinear matrix equation $X=Q+\sum_{i=1}^{m} M_{i} X^{\delta_{i}} M_{i}^{*}$ via a contraction principle. Linear Algebra Appl. 430, 1380-1383 (2009). doi:10.1016/j.laa.2008.10.034

41. Zhoua, B, Duana, G, Li, Z: Gradient based iterative algorithm for solving coupled matrix equations. Syst Control Lett. 58 327-333 (2009). doi:10.1016/j.sysconle.2008.12.004

42. Thompson, AC: On certain contraction mappings in a partially ordered vector space. Proc Am Math soc. 14, 438-443 (1963)

doi:10.1186/1687-1847-2012-38

Cite this article as: Khan et al:: Some convergence results for iterative sequences of Prešić type and applications. Advances in Difference Equations 2012 2012:38. 